\title{
Uma autobiografia sem fundamento ou o fundamento pela autobiografia: uma leitura de Bodenlos, de Vilém Flusser
}

\author{
Una autobiografía sin fundamento o el fundamento por la autobiografía: \\ una lectura de Bodenlos, de Vilém Flusser
An autobiography without foundation or the foundation by the autobiography: a reading of Bodenlos, by Vilém Flusser

\section{Daniel da Silva Moreira ${ }^{1}$}

\begin{abstract}
Resumo
O objetivo central deste texto é realizar uma leitura da autobiografia de Vilém Flusser, intitulada Bodenlos, evidenciando alguns dos mecanismos e estratégias de que o autor lança mão para abordar a "falta de fundamento". Além disso, este texto busca tocar, ainda que brevemente, na ligação entre o sem fundamento e a origem judaica do autor, na forte simbologia de algumas das cenas narradas e também na questão do exílio, que se faz presente ao longo de toda a obra.
\end{abstract}

Palavras-Chave: Vilém Flusser; Autobiografia; Exílio; Judeidade; Desenraizamento.

\section{Resumen}

El objetivo general de este artículo es realizar una lectura de la autobiografía de Vilém Flusser, titulada Bodenlos, poniendo de relieve algunos de los mecanismos y estrategias empleados por el autor para abordar la "falta de fundamento". Además, este artículo se propone tocar, aunque sea brevemente, la conexión entre el sin fundamento y el origen judío del autor, presente a través la significativa simbología de algunas escenas narradas e igualmente a través la cuestion del exilio, que es recurriente a lo largo de toda la obra.

Palabras claves: Vilém Flusser; Autobiografía; Exilio; Judeidad; Desarraigo.

\begin{abstract}
This article aims to propose a reading of Vilém Flusser's autobiography, entitled Bodenlos, highlighting some of the mechanisms and strategies used by the author to address the "lack of foundation". Furthermore, this text tries to touch, albeit briefly, on the connection between the lack of foundation and the author's jewish origins, on the strong symbolism of some of the scenes narrated, and also on the issue of exile, very present along the entire book.
\end{abstract}

Keywords: Vilém Flusser; Autobiography; Exile; Jewishness; Rootlessness.

\footnotetext{
${ }^{1}$ Doutor em Letras: Estudos Literários pela Universidade Federal de Juiz de Fora (UFJF); Juiz de Fora, Minas Gerais, Brasil; moreiradsm@gmail.com.
} 


\section{Apresentação}

O encontro de Vilém Flusser com o Brasil, como o de tantos outros intelectuais de sua geração, não foi exatamente uma escolha, mas antes um dos resultados do terror nazista que assolou a Europa e empurrou tantos para longe, para uma outra vida. Tendo chegado ao país em 1940 e aqui permanecendo até 1973, quando se muda para Robion, na França, Flusser desenvolveu uma ampla carreira intelectual, que incluiu a contribuição em importantes meios de comunicação, a docência em instituições reconhecidas e, claro, a publicação de livros.

Escrita muito provavelmente em meados dos anos de 1970, época em que Flusser deixa o Brasil para retornar à Europa, Bodenlos, palavra alemã que pode ser traduzida como "sem chão" ou "sem fundamento", é o título de sua autobiografia, chamada pelo autor também de "uma autobiografia filosófica". Em Bodenlos, Flusser articula toda sua autobiografia em torno da questão da falta de fundamento, de seu desenraizamento, empregando recursos da escrita autobiográfica que caminham claramente no sentido de construir uma fundamentação para a própria vida, valorizando, para usar suas próprias palavras, tudo que viesse se opor aos "aparelhos administrativos em função dos quais passamos grande parte das nossas vidas" (FLUSSER, 2007, p. 19). Isso equivale a dizer que a autobiografia de Flusser parece a todo momento buscar uma valorização dos "aparelhos" que têm fundamento, que contribuem para a criação de raízes, ao mesmo tempo em que denuncia todo o absurdo da vida humana. A frase "o presente livro atestará tal clima" [de absurdo, de falta de fundamento], repetida pelo autor no início da obra como um refrão ou o responsório de uma oração, de fato é cumprida; o livro denuncia o clima de falta de sentido e enraizamento em que se desenrolou a vida de Flusser, mas vai ainda além - e isso é justamente o mais interessante -, pois cria um mundo fundamentado a partir de sua narrativa, em que exercem um papel central os amigos, as cidades em que viveu, o prazer de ensinar e seu trabalho intelectual.

Evidenciar alguns dos mecanismos e estratégias de que Flusser lança mão para abordar a falta de fundamento e examiná-los mais detalhadamente é o objetivo central deste texto. Além disso, interessa-me tocar, ainda que apenas brevemente, na ligação entre o sem fundamento e a origem judaica do autor, na forte simbologia de algumas das cenas narradas e ainda na questão do exílio, que se faz presente ao longo de toda a obra.

\section{Uma autobiografia filosófica em que se diz "a gente"}


Antes de passar às questões centrais de meu texto, creio que seja importante fazer uma breve digressão para dar conta de dois temas cujo estudo se faz premente a partir da leitura de uma autobiografia como Bodenlos, que se poderia dizer um tanto atípica.

O primeiro ponto que me chama atenção é o possível efeito do uso do "a gente" sobre o narrador autobiográfico. Flusser escreve toda sua autobiografia utilizando, no lugar do "eu" ou mesmo do menos comum "nós", o "a gente", uma opção bastante intrigante justamente no tipo de texto literário caracterizado pela primeira pessoa do singular. É claro que essa é uma opção cuidadosamente pensada pelo autor, pois ao mesmo tempo em que impessoaliza o texto, por utilizar uma pessoa do discurso bastante afastada do "eu", o "a gente" é o pronome mais coloquial da língua portuguesa, gerando um efeito de proximidade e pessoalidade. $\mathrm{O}$ que me interessa é exatamente a mediação entre o pessoal e o impessoal, o que, em matéria de autobiografia, me faz pensar na tensão entre a autobiografia e as memórias. Philippe Lejeune, ao definir a autobiografia, coloca-a em contraste com o texto memorialístico: "A autobiografia é concebida como uma variante das memórias: uma narrativa referencial, que se quer verídica, escrita pela própria pessoa e centrada (em contraposição às memórias) mais na vida individual do que na história coletiva.” (LEJEUNE, 2008, p. 223). Desse modo, enquanto o texto autobiográfico daria conta da experiência individual, o texto memorialístico se estenderia em direção à coletividade, à história de um grupo, de uma geração ou mesmo de um povo. Minha teoria é que, ao incluir o "a gente" numa autobiografia, Bodenlos ganha a feição de um texto bilíngue, isto é, ocupa-se do pessoal e do particular, mas ao mesmo tempo avança em direção à representação da coletividade, da história do grupo a que pertence. Assim, a história da vida de Vilém Flusser, a maneira como ele a representa, acaba sendo também a história de todos os judeus, de todos os intelectuais e de todos os tchecos que se viram obrigados a abandonar o local em que habitavam face à ameaça nazista. Se a princípio poder-se-ia questionar que texto autobiográfico é esse que nem ao menos diz "eu”, é o próprio Lejeune que, já em seu primeiro ensaio sobre a autobiografia, nos diz que “(...) é obviamente possível escrever de outro modo do que na primeira pessoa. Quem me impediria de escrever minha vida me dizendo 'tu'?” (LEJEUNE, 2008, p. 17). Essa possibilidade de falar em variados níveis de vozes, com um considerável efeito sobre o discurso, evidencia os múltiplos recursos que as escritas de si podem ter nas mãos de alguém como Flusser, um rendimento que vai de encontro à opinião do senso comum sobre elas, normalmente vistas como um gênero plebeu, infantil e fácil (em oposição à arte, que exigiria trabalho e elaboração), ou seja, um gênero baixo, menor em todos os seus aspectos. 
O segundo ponto que, a meu ver, merece ser mencionado antes de dar prosseguimento ao texto refere-se ao subtítulo dado à obra: "uma autobiografia filosófica". A princípio essa denominação me causou certa estranheza, como uma autobiografia poderia ser filosófica? Não seriam todas elas filosóficas em certa medida? O que haveria de diferente em Bodenlos para que a obra recebesse esse subtítulo?

Minha primeira leitura foi de que a autobiografia filosófica tratar-se-ia simplesmente de uma espécie de subgênero da autobiografia intelectual, isto é, um subgênero da narrativa que busca reconstituir o caminho de uma formação. Contudo, além de não ter conseguido pensar ou localizar outros exemplos dentro da mesma proposta que pudessem servir a uma comparação e confirmar minha hipótese, a leitura atenta de Bodenlos chamou-me a atenção para uma característica do texto que, creio, elucide melhor a questão. Bodenlos seria uma autobiografia filosófica porque pensaria o tempo e a experiência humana de forma não convencional e questionadora, mais próxima do pensamento filosófico que do modo corrente - mas não predominante - de o texto autobiográfico representar a vida. Há que se dizer, entretanto, que essa forma de pensar o tempo nessa narrativa não segue a todo instante o modo grego de vivenciá-lo, tão importante para a filosofia, mas se aproxima muitas vezes do tempo hebraico, da forma como as escrituras lidam com a questão. Handelman, ao contrastar as duas formas de representar o tempo, nos diz que "O presente grego é definido pelo lugar em que a ação aconteceu e estamos lá como espectadores e testemunhas. O presente hebraico, todavia, é fluido, contém tanto o passado quanto o futuro simultaneamente." (HANDELMAN, 1982, p. 37, tradução minha). Flusser oscila entre as duas concepções temporais, ele mesmo se dando conta dessa alternância: "Até aqui o presente livro tem seguido linha aproximadamente cronológica, embora tal linha esteja aberta a sérias dúvidas de vária ordem.” (FLUSSER, 2007, p. 119). O autor prossegue, chamando a concepção do tempo como uma linha que partiria do passado em direção ao futuro de "método falsificador da memória", pois haveria momentos impossíveis de serem quantificados segundo regras gerais e, ainda, porque nem sempre o que se coloca "antes" aconteceu mesmo "antes".

Essas duas características, em grande medida, dão esse caráter único de que falei anteriormente à autobiografia de Vilém Flusser. Por conta delas e também pelo próprio estilo do autor, seu texto, que à primeira vista parece bastante impessoal e em que não se diz "eu" (exceto, obviamente, nos capítulos traduzidos por Raquel Abi-Sâmara, a partir do alemão,

\footnotetext{
${ }^{2}$ No original: "The Greek present is defined by the place where the action takes place, and we are there as spectators and witnesses. The Hebrew present, however, is fluid, containing both past and future simultaneously."
} 
sobre o que tratarei mais adiante), resulta numa narrativa rica, transmissora de uma experiência profundamente pessoal.

\section{A ausência de fundamento}

O que é não ter fundamento? O que é ser Bodenlos? No princípio da autobiografia de Vilém Flusser o leitor é apenas apresentado ao conceito, fica-se sabendo que Bodenlos equivale a "sem chão", "sem fundamento" e ainda a tudo que seja absurdo. É aos poucos que se vai tomando contato com a origem dessa perda de raízes, que parece, a meu ver, o fio condutor de sua narrativa, toda ela articulada em torno dessa questão. $\mathrm{O}$ autor escreve sua autobiografia com o intuito expresso de, a partir dela, atestar essa experiência de perda de fundamento e, o que parece ser mais importante, compartilhá-la com outros, para que "sirva de espelho" e de "laboratório" (FLUSSER, 2007, p. 21). Ainda que reconheça que seja impossível transformar essa experiência em literatura, filosofia e arte sem que haja uma espécie de falsificação, o autor aceita resignadamente que a transformação ocorra apenas parcialmente. Flusser diz ainda que falar sobre a falta de fundamento causa sua destruição: "É ela a experiência da solidão, e derrete, quando discutida publicamente.” (FLUSSER, 2007, p. 21), numa declaração que pode ser entendida de duas formas, ou falar faz com que o sem fundamento desapareça por não conseguir alcançar sua complexidade, ou o exercício de articulação em torno do tema de algum modo contribui para exorcizá-lo. Escolho pensar Bodenlos a partir da segunda alternativa, pois creio que ela esteja muito mais próxima da experiência de partilha proposta por Flusser; que, longe de significar um apagamento das causas e das consequências do desenraizamento, significa muito mais sua apropriação numa atitude "didática", de evitar, talvez, recorrências futuras. Essa noção de falta de fundamento está também ligada, como é possível constatar ao longo de Bodenlos, à situação de eterno ou contínuo exílio do povo judeu, vivenciada como "uma punição catastrófica de seus pecados". 3

\section{Um monólogo}

O prefácio de Gustavo Bernardo chama a primeira parte de Bodenlos, o Monólogo, de "emocionante": "Para qualificar essa primeira parte eu usaria um adjetivo que talvez Vilém não gostasse muito: emocionante. Emociona como se lêssemos um romance (...)" (BERNARDO, 2007, p. 11). Penso que usar essa caracterização para essa parte da obra pode

${ }^{3}$ Cf. JACOBS, Louis. Exile. In: The Jewish religion: a companion. Oxford: Oxford University Press, 1995. P. 157. 
dar uma impressão equivocada da narrativa de Flusser, isso porque parece que se considera tudo o que está contado ali como decalque fiel da realidade, quando na verdade trata-se antes de uma representação de uma realidade, com elementos escolhidos cuidadosamente. O senso comum muitas vezes pensa a escrita autobiográfica em termos de "verdade" e não em termos de representação intencional, como se a vida criasse a escrita, quando, como diz Philippe Lejeune, “é o texto que produz a vida!” (LEJEUNE, 2008, p. 65). Além disso, uma afirmação como a de Gustavo Bernardo encobre uma das propriedades mais marcantes dessa primeira parte de Bodenlos: seu caráter profundamente simbólico, isto é, algumas das cenas narradas pelo autor são de tal modo carregadas de simbologia que, assim penso, vê-las como mero relato de uma experiência acontecida seria um empobrecimento que deixaria de lado todas as elaborações complexas de Flusser.

A primeira parte de Bodenlos poderia muito bem ser lida como uma "viagem", não exatamente como nas autobiografias tradicionais (que muitas vezes partem da ideia da vida como um percurso, uma caminhada), mas como uma viagem de transformação e mesmo de salvação, que equivaleria à passagem da Europa ameaçada pelo nazismo ao distante e exótico Brasil, em que se antevê alguma esperança de vida, ainda que a falta de fundamento esteja presente de um espaço ao outro.

O primeiro lugar a que o leitor é apresentado é à Praga habitada por Flusser, representada logo de entrada como um berço civilizatório: "Poucas cidades deram o salto para se tornarem berços de civilização, e Praga é uma delas. (...) Quem visita tais cidades, deve amá-las ou odiá-las. E quem nelas nasceu e viveu, deve aceitá-las como centro do mundo. Sum ciuis Pragensis." (FLUSSER, 2007, p. 23-24). Praga estaria, também em suas palavras, "no núcleo da gente" (FLUSSER, 2007, p. 26). A cidade poderia resolver mesmo a dúvida identitária entre ser tcheco, alemão ou judeu com a simples resposta "ser praguense", pois teria a capacidade de sintetizar diferentes identidades. Diante dela qualquer nacionalismo perderia seu sentido de ser e, ao mesmo tempo que lembra a antiga polis grega, Praga faz pensar num modelo de cidadania muito à frente de seu tempo.

O principal símbolo representado por Flusser nesse momento é essa Praga que parecia indissolúvel, indestrutível e que oferecia tantas possibilidades identitárias:

A estreiteza de Praga era encoberta por sua profundidade. Pois isto é sintoma de estar-se abrigado: tomar-se como centro do mundo. É claro: sabia-se que o centro estava periclitando. A curto prazo pela barbárie nazista; a longo prazo pelas modificações profundas na vasta cena do globo. Sabia-se que, vista de tal vastidão, Praga era anacronismo. Mas existencialmente não se tomava conhecimento disto. Praga, isto é a realidade, e como pode desaparecer a realidade? Os nazistas que se 
aproximam, e os chineses que se concentram no além do horizonte, isto é que é fantasia. Diante da realidade eterna dos muros de Praga se dissolverá tal fantasia. Praga é eterna: se ela desaparecesse, desapareceria tudo. (FLUSSER, 2007, p. 3031)

É Praga, tal como se caracteriza nesse momento (apesar de pequena, muito complexa), que permite uma vida com fundamento, o sentimento íntimo de "estar-se abrigado". Convive-se com as ameaças à cidade porque, contrastadas com sua eternidade e força, elas parecem meras obras da imaginação. Tudo em que se acredita é na perenidade de Praga; se ela desaparecesse, tudo no mundo desapareceria, porque ela é o mundo.

Mas é o próprio Flusser que prossegue, dizendo: "Pois tudo desapareceu." (FLUSSER, 2007, p. 34). O avanço das tropas alemãs foi tomando as "cidades irmãs" e o autor dá continuidade ao reforço do simbolismo de Praga, ao mesmo tempo em que evidencia o sem fundamento da ocupação nazista. Até mesmo o sionismo, antes visto com desconfiança - e mesmo como desnecessário, pois Praga oferecia algo mais concreto -, torna-se algo possível, palpável. A Praga física prepara-se para ser invadida, enquanto a Praga interna, aquela "no núcleo da gente" (FLUSSER, 2007, p. 26), tenta resistir: "Mas o solo fundante, Praga, continuava intacto, e a sua tarefa era preparar-se para a luta árdua e longa contra os nazistas. Mas a gente mesma estava perdendo o chão debaixo dos pés, e preparava-se para ser assassinada." (FLUSSER, 2007, p. 35). A pressão dos invasores, contudo, é insuportável e seu absurdo está simbolizado pelo autor através do desejo recorrente de que os nazistas o assassinassem o mais rápido possível: "A esperança de ser assassinado rapidamente pelos nazistas crescia. Última esperança.” (FLUSSER, 2007, p. 35). Até mesmo as relações afetivas são destruídas, os amigos de origem alemã que vivem em Praga são vistos com crescente desconfiança, como "chacais dos lobos nazistas". "A falta de fundamento tinha se iniciado" (FLUSSER, 2007, p. 38), diz Flusser ao perceber que a única alternativa era a fuga, o "sacrifício da dignidade em prol da sobrevivência do corpo" (FLUSSER, 2007, p. 37).

A partida de Praga é representada através de uma cena extremamente simbólica, que ilustra muito bem a passagem do fundamento à sua ausência:

Mas os dois livros que acompanharam a gente na fuga (únicos bens materiais) não eram de Nietzsche. Era o Fausto de Goethe (por causa de Mefistófeles, não Fausto) e um livro de preces judeu. O livro de preces, aparentemente porque foi a mãe já morta que o botou nas mãos da gente (uma mãe da qual se tinha ignorado toda religiosidade), mas na realidade por razões então e agora ignoradas. O livro de preces (mas não Fausto) se perdeu durante a fuga. (FLUSSER, 2007, p. 39) 
Este pequeno episódio tem inúmeros significados possíveis. O primeiro que se me afigura é o de que não se vai vazio para o exílio, leva-se sua cultura, seu modo de vida, sua forma de ver o mundo; nesse sentido, os únicos bens materiais que Flusser diz ter levado são bastante representativos, pois são justamente dois livros, simbolizam mais o que vai dentro do homem do que os objetos em si. Um deles, o Fausto, representa toda a matriz cultural europeia, é a obra literária mais importante da literatura de língua alemã e, é importante notar, o autor se vê ligado a ela de um modo muito particular, atraído não pela personagem que seria talvez a escolha da maioria, Fausto, mas por Mefistófeles, o demônio. Considerado símbolo cultural da modernidade, Fausto descreve o drama do Doutor Fausto, um homem das ciências que, desenganado com o saber de seu tempo, faz um pacto com o demônio Mefistófeles, que em troca lhe dá a energia satânica insufladora da paixão pela técnica e pelo progresso. Creio que essa identificação possa estar relacionada justamente a esse "poder" possuído por Mefistófeles, de fazer crer em algum progresso mesmo quando já se desistiu de tudo. O outro volume levado na fuga, oferecido pela mãe do autor, é um livro de preces judeu, que Flusser alega ter perdido no caminho. É bastante simbólico esse conjunto de obras, representando de um lado a tradição cultural/intelectual e de outro a tradição religiosa/familiar; mais simbólico ainda é o fato, marcado de modo recorrente, de o livro de preces ter se perdido, mas de o Fausto ter continuado como companhia de viagem. Aliado a tudo isso, ainda está presente o "a gente" de Flusser, que parece querer lembrar a todo instante que essa história é a de cada um dos judeus que decidiram deixar para trás seus fundamentos.

Flusser termina dizendo que "assim Praga morreu", o que significava que "doravante não se pertencia mais a ninguém e a lugar nenhum, era-se independente", obviamente uma grande perda, mas que implicava também num modo diferente de observar a realidade: "A gente olhava tudo isto de cima. E tal visão abria horizontes de um céu infinito. Doravante tudo era possível. E para dentro de tal possibilidade sem limite a gente se precipitava, de coração sangrento, mas de espírito aberto" (FLUSSER, 2007, p. 39). Assim, é possível perceber que convivem lado a lado um "coração sangrento", marcado pela antevisão do desterro, pela perda da família e pelo abandono da cidade amada, e um "espírito aberto", capaz de conduzir a uma outra vida.

No entanto, o primeiro destino encontrado não se mostra tão adequado; uma vez na Inglaterra, Flusser dá-se conta de que "Londres ou Johanesburgo, pouco importa. Nomes vazios.” (FLUSSER, 2007, p. 41). Isso porque chega à conclusão de que não basta ter um solo para voltar a ter fundamento e se pergunta: "Será que a derrocada do fundamento não passava de experiência subjetiva?”. Essa experiência subjetiva continua a conviver com uma atração 
mórbida pela morte. Quando a Inglaterra parece que pode ser invadida pelos alemães, que já a sobrevoam e aterrorizam com seus aviões bombardeiros, é hora de tomar mais uma decisão de partir:

\begin{abstract}
Era necessário emigrar para territórios inteiramente exóticos e fantásticos, nos quais a gente era automaticamente sombra. Para territórios inteiramente fora de toda realidade. Para a Tailândia ou o Brasil, por exemplo. É claro e deve ser confessado: a decisão para a emigração era parcialmente motivada pelo medo da morte do outro. Mas apenas parcialmente. $\mathrm{O}$ verdadeiro motivo era abandonar a realidade em definitivo. (FLUSSER, 2007, p. 46)
\end{abstract}

A partida é vivenciada como fuga da realidade, pois em meio à guerra só há como viver fisicamente, a dimensão intelectual fica totalmente adormecida, por conta da perda de fundamento. E justamente porque se perdeu o fundamento e se deu conta de que essa perda é um traço subjetivo - e, portanto, acompanha sua vítima aonde quer que ela vá - é que a única saída que se vê seria migrar para o local mais exótico possível, onde a existência, ao menos era o que se esperava, não implicasse nos mesmos mecanismos sociais, agora destruídos no local de origem.

O lugar "exótico" escolhido foi o Brasil, mais especificamente a cidade de São Paulo, uma experiência vivenciada, a princípio, como extremamente positiva: "Quando se desembarca nas costas brasileiras, não é novo espaço que se encontra, mas tempo novo, ou pelo menos diferente." (FLUSSER, 2007, p. 47). Enfim chega-se ao ponto de destino dessa "viagem". A São Paulo em "puberdade" e em que "sopra o espírito de um tempo diferente" choca Flusser, pois ele a coloca imediatamente em contraste com a Praga que naquele mesmo momento agoniza. Mas, segundo o autor, a percepção de quem está em agonia e de quem está em prosperidade é completamente intercambiável para aqueles que, como ele, percebem o mundo a partir da falta de fundamento. O Brasil, como a guerra, se apresenta como uma outra irrealidade, não como algo provisório como para a maioria dos migrantes. O pensamento fixo da morte ainda o persegue nos primeiros tempos: "Este o clima existencial dos primeiros anos em São Paulo: os fornos nazistas no horizonte, o suicídio pela frente, os negócios de dia, a filosofia de noite.” (FLUSSER, 2007, p. 50). Contudo, ao lado dela, ainda que precariamente, a vida começa a se estabelecer, com "os negócios de dia" para a subsistência do corpo e com "a filosofia de noite" para a subsistência da mente.

É assim que a falta de fundamento começa a ceder "porque a gente começava a descobrir o calor humano emanado pelos brasileiros" (FLUSSER, 2007, p. 75), diz um Flusser dedicado a estudar a "natureza brasileira", tanto a natural quanto a humana. As 
primeiras relações afetivas, os primeiros amigos, começam a aparecer, especialmente nas pessoas de Guimarães Rosa e Dora Ferreira da Silva. Um dos grandes obstáculos encontrados para um "engajamento" na sociedade brasileira, de acordo com Flusser, seria o fato de que, enquanto em Praga a sociedade estava hierarquizada em níveis de cultura - e ele ocupava um lugar alto -, em São Paulo a hierarquia era econômica - e seu lugar nela relativamente baixo. A saída que o autor diz ter encontrado para superar este obstáculo foi um engajamento na cultura brasileira, a partir do qual ele "passava (...) a reassumir o mesmo papel social que o nascimento tinha reservado" (FLUSSER, 2007, p. 82). Assim, é através da atividade cultural que Flusser começa a se reinserir no mundo, a criar algumas raízes. O contato com a cultura brasileira fará com que tome a decisão de "agir" dentro dessa cultura, gerando então uma ruptura profunda e uma considerável mudança na sua forma de estar no mundo:

\begin{abstract}
Nos primeiros dez anos de vida brasileira, a cultura do país era para a gente uma entre muitas, que a gente observava a partir da distância proporcionada pela falta de fundamento. E, subitamente, a gente tomou a decisão (...) de engajar-se nela (...). De passagem seja dito que isto explica, em parte, o fato curioso de que doravante a gente se sentia muito mais ligada a "brasileiros natos" que aos imigrantes. (FLUSSER, 2007, p. 89-90)
\end{abstract}

Esse engajamento virá, inicialmente, na forma de contribuições para o Suplemento Literário do Estado de São Paulo, o que fez ainda com que Flusser se aproximasse da língua portuguesa, uma vez que seria ela seu meio de ação e conquista de espaço:

Destarte a língua portuguesa passou a ser instrumento apaixonante para jogo infinito, instrumento este que mudava, ele próprio, ao longo do jogo. E com isto a própria gente mudava. Em outros termos: a gente se transformava, disciplinada e entusiasticamente, em ensaísta brasileiro. (FLUSSER, 2007, p. 106-107)

É possível perceber que a partir desse momento, de contato intenso com a cultura brasileira, há um considerável ganho e, dessas várias pequenas conquistas, o fundamento vai se firmando, ao menos na narrativa.

\title{
5. Os diálogos
}

Em contraste com a primeira parte da obra, em que Flusser fala apenas de sua experiência, daí o título de Monólogo, Diálogo vai tentar dar conta de sua relação com onze intelectuais $^{4}$ - alguns brasileiros, outros imigrantes como ele -, com os quais entrou em

\footnotetext{
${ }^{4}$ São eles: Alex Bloch, Milton Vargas, Vicente Ferreira da Silva, Samson Flexor, João Guimarães Rosa, Haroldo de Campos, Dora Ferreira da Silva, José Bueno, Romy Fink, Miguel Reale e Mira Schendel.
} 
contato durante os anos em que esteve no Brasil. No contexto do jogo da presença e da ausência de fundamento, o que Flusser faz em Diálogo vai representar um papel fundamental no seu processo de aproximação com o Brasil.

Creio que seja possível traçar um paralelo entre o processo de seleção de figuras afetivas e intelectuais de Flusser e a organização de álbuns de fotos de família, tal como descrita por Philippe Artières em "Arquivar a própria vida":

\begin{abstract}
Vejamos nesse sentido a prática do álbum de fotos de família (...). Em toda família, existe com efeito o hábito de dedicar regularmente longas tardes a reunir e a organizar as fotos relacionadas com a vida de cada um dos seus membros. Um casamento, um nascimento, uma viagem são objeto de uma ou de várias páginas. Não colamos qualquer foto nos nossos álbuns. Escolhemos as mais bonitas ou aquelas que julgamos mais significativas; jogamos fora aquelas em que alguém está fazendo careta, ou em que aparece uma figura anônima. E depois as ordenamos esforçando-nos para reconstituir uma narrativa. Quando a foto é muito enigmática, acrescentamos um comentário. Quando uma visita chega, começa a cerimônia das fotos, fazem-se observações, viram-se algumas páginas rapidamente. (...) No álbum, fazemos figurarem também os nossos antepassados; aí também trata-se de comprovar que pertencemos a uma linhagem, que temos raízes. (...) Se as ausências nos álbuns são toleradas, não manter arquivos fotográficos da família, em compensação, constitui uma falta. É um dever produzir lembranças; não fazê-lo é reconhecer um fracasso, é confessar a existência de segredos. O álbum é uma garantia de transparência, um passaporte de sinceridade e uma prova de ajustamento. (ARTIÈRES, 1998, p. 14, grifo meu)
\end{abstract}

Desse modo, as onze personalidades colocadas no álbum autobiográfico de Vilém Flusser têm, cada uma delas, sua razão de ser. Ao reunir essa expressiva coleção de referências afetuosas, que perturbam intelectualmente - e, em direção oposta, são por ele perturbadas e admiradas -, forma-se sua pequena legião de amigos, que permitem a resistência a um mundo em que não se tem mais fundamento, ao mesmo tempo em que recriam o fundamento através de suas presenças e comunhões. Como os antepassados que são colocados em todos os álbuns, esses amigos mostram a linhagem intelectual a que se pertence, mostram "que temos raízes". O reconhecimento da importância da amizade é, ao mesmo tempo, íntimo e profissional, o que só torna mais rica toda essa vasta rede de contatos. É interessante também pensar a reabertura de Flusser a esse tipo de amor, mesmo depois do trauma da perda de raízes e dos amigos em que não se tinha mais certeza de que era possível confiar. Aceitar tantas novas relações é sempre correr um risco, o que faz parte do processo de hospitalidade: “a hospitalidade vale para a passagem das fronteiras de um país, mas tem um papel também na 
vida corrente: quando alguém chega, quando o amor chega, por exemplo, assume-se um risco, uma exposição" (DERRIDA, ROUDINESCO, 2004, p. 77). A prática de enfileirar seus amigos em Bodenlos se relaciona com a hospitalidade àquele que chegou ao país expulso de sua terra natal, mas também cria uma hospitalidade para si, uma auto-hospitalidade, que fornece, ao menos no plano da narrativa autobiográfica, uma fundamentação para a vida passada no Brasil.

O último capítulo da seção Diálogo, intitulado "O terraço", só vem a confirmar essa dinâmica de valorização da amizade, pois opera como uma síntese de todos os diálogos. O terraço em questão seria a parte da casa de Flusser no Brasil onde esses diálogos tiveram lugar: "No terraço dá de cara com os amigos empenhados em diálogo violento que formam círculo grande ou vários pequenos.” (FLUSSER, 2007, p. 255). E, é importante que se diga, há "um número de figuras que é excessivo para ser enquadrado no presente trabalho" (FLUSSER, 2007, p. 255), ou seja, há mais presenças além daquelas onze que ele nomeia e sobre as quais desenvolve um pequeno ensaio. Não fica de fora dessa seção um tipo de narrativa frequente em escritos autobiográficos: o acerto de contas. Flusser parece se defender daqueles que o acusaram de conservador ou reacionário justamente por atitudes suas que ele chama de "atitudes críticas".

\section{O discurso e as reflexões}

A penúltima seção de Bodenlos, intitulada Discurso, tem por intuito evocar aqueles aspectos da vida pelos quais, de acordo com Flusser, ele tentou modificar o mundo, seus "engajamentos". O discurso seria a forma tomada pelas múltiplas tentativas de modificação da realidade e, nesse contexto, Bodenlos representa o "último elo da cadeia do (...) engajamento" (FLUSSER, 2007, p. 265). É como professor e como escritor que Vilém Flusser encontra os meios para exercer seu engajamento, dividido entre o falar e o escrever.

Por fim, há uma seção denominada Reflexões, que de início estabelece uma relação entre a pátria e o hábito. Os capítulos que a compõem foram escritos por Flusser apenas em alemão, de modo que o que se lê é uma tradução de uma terceira pessoa, e o principal resultado é que não se diz mais "a gente". Ainda assim, há algumas considerações do autor sobre a questão da migração e do exílio que julgo importantíssimas para concluir meu pensamento. Em primeiro lugar, a questão dos exilados é reavaliada no sentido de que não sejam vistos como um grupo vitimizado, que sempre quer - e para isso precisaria de auxílio voltar para o lar perdido, mas sim como modelos a serem seguidos por sua ousadia: 
Os vietnamitas na Califórnia, os turcos na Alemanha, os palestinos nos países do Golfo Pérsico e os cientistas russos em Harvard surgem não como vítimas dignas de compaixão que devem receber ajuda para retornar à pátria perdida, mas sim como modelos a serem seguidos por sua suficiente ousadia. Pensamentos desse tipo, no entanto, são admissíveis apenas a expatriados e migrantes, não aos agentes da expatriação ou àqueles que ficam. Pois a migração é uma atividade criativa, mas, também, um sofrimento. (FLUSSER, 2007, p. 296)

É como se Flusser reconhecesse que, após um longo percurso, a experiência do exílio tenha tido também uma dimensão que impulsionou em direção à criatividade e ao novo, o que não significa de modo algum o apagamento do trauma e do sofrimento, e é justamente por isso que pensamentos sobre o "lado feliz" do desterro seriam permitidos apenas para os exilados e migrantes, nunca para os responsáveis pelo exílio e para os que ficaram para trás.

Assim como Flusser, em excerto citado anteriormente, tinha declarado sentir-se naquele momento mais ligado aos "brasileiros natos" que aos imigrantes, já perto do fim de sua autobiografia o autor se dá conta de um fato no mínimo intrigante:

(...) experimentei duas coisas que se contradizem: todos os homens com quem estive ligado em Praga foram exterminados. Todos. Os judeus, em câmaras de gás, os tchecos, na resistência, os alemães, em campanha russa. Todos os homens com quem estive ligado em São Paulo estão vivos, e continuo em contato com eles. Paradoxalmente, o rompimento do nó górdio de Praga foi mais fácil do que o do nó paulistano, embora o mistério que me ligasse a Praga fosse mais sombrio do que no caso de São Paulo. Uma experiência macabra, sem dúvida. (FLUSSER, 2007, p. 299)

Mesmo depois de decidir deixar o Brasil e ir viver no interior da França, as relações afetivas e intelectuais do autor continuaram sendo predominantemente brasileiras, e ainda que o "nó" de ligação com São Paulo tenha se rompido, ele registra que houve mais dificuldade que quando da separação de Praga. O recurso encontrado pelo autor para lidar com esses constantes rompimentos - nesse ponto quase não se fala mais em ausência de fundamento - parece ser um acúmulo de identidades, pautadas antes de tudo pela liberdade, que permitiria escolher e desenvolver as relações humanas de modo independente de atrelamentos geográficos:

Creio que isso mostra o que significa ser livre. Não é cortar as ligações com os outros, mas sim tecer essas ligações em trabalho conjunto, em cooperação com eles. Não é negando a pátria perdida que o migrante se torna livre, mas sim quando ele a sustém (...). Sou praguense, paulistano, robionense e judeu, e pertenço ao círculo de cultura chamado alemão, e eu não nego isso, mas sim o acentuo para poder negá-lo. (FLUSSER, 2007, p. 300) 
A liberdade não se conquista negando o que foi deixado para trás, mas sim acumulando e acentuando as novas identidades e pertencimentos; só assim pode haver uma negação e um distanciamento que garanta o "ser livre".

O fim de Bodenlos guarda uma última cena de forte simbologia; 52 anos depois de ter deixado Praga, Flusser volta à cidade e tudo o que vê parece estranho, muito diferente da Praga que habitava sua memória. O reencontro é ainda mais intrigante quando se sabe que poucos dias depois, nessa mesma Praga, Vilém Flusser sofreria um acidente que lhe tiraria a vida. O que existe entre o que se lembra e o que se experimenta no retorno não é apenas a diferença de percepções, é muito mais a tragédia que arrancou seus fundamentos, que moldou sua vida:

O que inicialmente eu, como rapaz, corria com pressa e sem fôlego para poder chegar a tempo na aula de latim, e o que eu hoje, como pessoa de idade, percorro sem fôlego para reencontrar a mim mesmo, é a fatalidade inominável que o século 20 deixou acontecer no palco grandioso de Praga. Essa fatalidade da qual eu fui feito. Esta é a trilha que eu encontrei: a suntuosidade indescritível como palco da catástrofe indescritível. (FLUSSER, 2007, p. 325-326)

\section{Considerações finais}

Atravessada pela falta de fundamento, pelo desenraizamento, Bodenlos parece criar, a todo instante, um ponto de equilíbrio dentro dessa vida recriada em narrativa, em que a completa ausência de fundamento caminha no sentido de ser compensada por uma série de fatores. Nesse contexto, espero que meu texto tenha sido capaz de lançar luz sobre algumas das estratégias utilizadas para a abordagem, a denúncia e a compensação do absurdo. Não que seja uma negação do sofrimento; esse é sabido que nunca cessa em quem vê seu mundo desmoronar tão rápido e em uma situação tão cruel. Mas ver que mesmo assim há a possibilidade de resistência, que os novos amigos, o engajamento cultural, as pequenas conquistas podem trazer o fundamento perdido de volta, ou ao menos uma parte dele, é algo reconfortante e faz da narrativa de Bodenlos uma reflexão única, viva e instigante sobre um dos maiores dramas da história da humanidade.

\section{Referências}

ARTIÈRES, Philippe. Arquivar a própria vida. Estudos Históricos, Rio de Janeiro, v.11, n.21, 1998 .

BERNARDO, Gustavo. A gente de Flusser. In: FLUSSER, Vilém. Bodenlos: uma autobiografia filosófica. São Paulo: Annablume, 2007. 
DERRIDA, Jacques, ROUDINESCO, Elisabeth. De que amanhã... Diálogo. Trad. André Telles. Rio de Janeiro: Jorge Zahar, 2004.

FLUSSER, Vilém. Bodenlos: uma autobiografia filosófica. São Paulo: Annablume, 2007.

HANDELMAN, Susan A. Rabbinic thought: the divinity of the text. In: The Slayers of Moses: the emergence of rabbinic interpretation in modern literary theory. Albany: State University of New York Press, 1982. P. 27-50.

JACOBS, Louis. Exile. In: University Press, 1995. P. 157. . The Jewish religion: a companion. Oxford: Oxford

LEJEUNE, Philippe. O pacto autobiográfico - de Rousseau à internet. Trad. Jovita Maria Gerheim Noronha e Maria Inês Coimbra Guedes. Belo Horizonte: UFMG, 2008. 